\title{
O TRABALHO NOS APLICATIVOS DE ENTREGA DE MERCADORIAS: A DESCONSTRUÇÃO DO SUJEITO DE DIREITOS TRABALHISTAS
}

\section{LABOR IN DELIVERY APPS: THE DECONSTRUCTION OF SUBJECTS OF LABOR RIGHTS}

\author{
RENATA QUEIROZ DUTRA ${ }^{1}$ \\ GABRIELA SEPÚLVEDA ${ }^{2}$
}

RESUMO: Na última quadra do capitalismo, já transformado pelo viés da acumulação flexível e da reestruturação produtiva pós-fordista, a perspectiva neoliberal associada ao desenvolvimento tecnológico que se coloca a seu serviço tem dado espaço para novas conformações e dinâmicas empresariais que impactam as relações laborais. Neste cenário de constantes mudanças e aprimoramento das tecnologias, surgem os aplicativos de entrega, tais como Rappi, Glovo, Uber Eats e iFood. Com o advento destas novas tecnologias, emerge um desafio para o direito do trabalho que reside não apenas na supressão de direitos ou flexibilização das condições laborais, mas na negação da existência da própria relação de trabalho, já que as plataformas se apresentam como sujeitos empresariais responsáveis somente pela intermediação entre os usuários do aplicativo e os entregadores cadastrados, sem supostamente estabelecer vínculo de emprego com estes. À luz dessa nova realidade, o desafio desse artigo é repensar as categorias do sujeito do direito do trabalho e da relação de emprego, com base na perspectiva do direito fundamental ao trabalho digno, a fim de apresentar uma contribuição à resistência do campo juslaboral ao fenômeno da uberização.

Palavras-chave: Aplicativos de entregas; Uberização; Flexibilização; Sujeito de direitos trabalhistas; Trabalho digno.

\footnotetext{
${ }^{1}$ Professora Adjunta de Direito e Processo do Trabalho da Universidade de Brasília. Doutora e Mestra em Direito, Estado e Constituição pela Universidade de Brasília. Contato: renataqdutra@gmail.com.

2 Universidade Federal da Bahia. Graduada em Direito. Membro do Grupo de Pesquisa "Transformações do trabalho, democracia e proteção social" (UFBA/CNPq). Contato: gabriela.sepulveda.08@gmail.com
} 
ABSTRACT: In the last block of capitalism, already transformed by the bias of flexible accumulation and post-Fordist productive restructuring, the neoliberal perspective associated with the technological development that is at its service has given rise to new conformations and business dynamics that impact labor relations. In this scenario of constant changes and improvement of technologies, delivery apps, such as Rappi, Glovo, Uber Eats and iFood, have appeared. With the advent of these new technologies, a challenge for labor law arises that lies not only in the suppression of rights or in the easing of working conditions, but in the denial of the existence of employment relationship itself, since the platforms present themselves as responsible corporate subjects only by intermediating between users of the application and registered deliverers, without supposedly establishing employment links with them. In the light of this new reality, the challenge of this article is to rethink the categories of the subject of labor law and the employment relationship, based on the perspective of the fundamental right to decent work, in order to make a contribution to the resistance of the labor field to the phenomenon of uberization.

Keywords: Delivery apps; Uberization; Flexibilization; Subjects of labor rights; Decent work.

\section{INTRODUÇÃO}

As relações de trabalho têm se metamorfoseado numa velocidade ímpar, sendo diuturnamente impactadas pelas novas tecnologias digitais. Ao tempo em que prometem aproximar pessoas e oferecer facilidades à vida moderna a um baixo custo, as novas plataformas digitais que engajam trabalho têm operacionalizado esse rentável projeto por meio da desconstrução ou da recusa das formas jurídicas conhecidas e tuteladas pelo direito do trabalho.

Os impactos sobre as condições de trabalho são múltiplos e preocupantes. E o direito do trabalho, que nas últimas duas décadas tem vivenciado um ciclo crítico, porque cada vez mais tensionado pela agenda (ou racionalidade) neoliberal (DARDOT; LAVAL, 2016), tem sido desafiado a capturar e a, quiçá, responder a esse potente fenômeno.

Entre os múltiplos e interessantes debates que se tem travado a respeito do tema, buscaremos nesse artigo contribuir com a discussão a partir da ótica da desconstrução do sujeito de direitos trabalhistas. Se é verdade que a estratégia da uberização ${ }^{3}$ tem se concretizado por meio da burla aos mecanismos de

\footnotetext{
${ }^{3}$ Por uberização do trabalho, entendemos a "nova forma de gestão, organização e controle do trabalho que se afirma como tendência global no mundo do trabalho", caracterizando-se pelo desenvolvimento de novas formas de dispersar o trabalho sem perder o controle sobre ele, por
} 
regulamentação do direito do trabalho, com subsequente fragilização das dinâmicas de regulação prevalecentes no nosso tempo histórico, a retórica por trás desse discurso desafia o campo juslaboral, entre outros aspectos, por meio da negação da condição de sujeito de direitos trabalhista aos trabalhadores engajados nessa condição.

Nesse artigo, resgataremos, inicialmente, o contexto da reestruturação produtiva e o caminho percorrido até as últimas transformações tecnológicas verificadas, de modo a desvelar o cenário de transformações do trabalho e de sua regulação. Em seguida, debateremos o cenário da uberização e sua desconformidade com a perspectiva do direito fundamental ao trabalho digno, enquanto paradigma jurídico de inclusão. Por fim, debateremos em que medida há um deslocamento do conceito e das características do sujeito de direitos trabalhistas nessa nova conjuntura, de modo a resgatar premissas que possam auxiliar na resistência do campo juslaboral ao fenômeno que tem importado, em grande medida, em sua negação.

A consecução do artigo se assentará em revisão bibliográfica da literatura interdisciplinar subjacente ao mundo do trabalho, com amparo no método dialético.

\section{TRANSFORMAÇÕES DO TRABALHO, REESTRUTURAÇÃO PRODUTIVA E NOVAS REVOLUÇÕES TECNOLÓGICAS ${ }^{4}$}

As recentes transformações no mundo do trabalho não se desconectam do processo de reestruturação produtiva que marcou o final do século $X X$ : do contrário, o aprofundam, radicalizando suas premissas e multiplicando suas consequências em termos de precarização social do trabalho.

$\mathrm{O}$ final do século $\mathrm{XX}$ foi marcado por grandes transformações na ordem econômica mundial. Ao cabo da década de 1970, o capitalismo enfrentou significativa crise, decorrente da redução dos níveis de produtividade (com a queda da taxa de lucros, esgotamento dos modelos taylorista e fordista de produção, que não se mostraram aptos a responder ao desemprego estrutural), da hipertrofia da esfera financeira, da excessiva concentração de capitais decorrente da formação de monopólios e oligopólios, da falência do modelo de Estado Social, do crescimento acentuado das privatizações e da tendência à flexibilização e desregulamentação protetiva dos mercados e do trabalho (ANTUNES, 1999, p. 31-32).

Esse contexto foi caracterizado também pelo desenvolvimento do processo de globalização, que decorreu da generalização do sistema capitalista, da nova revolução tecnológica (a chamada Terceira Revolução Industrial) e da hegemonia financeiro-especulativa, com a priorização da reprodução capitalista através da

meio do engajamento de "autogerentes-subordinados" via adesão às plataformas digitais que se traduzem em "empresas-aplicativo" (ABÍLIO, 2019).

${ }^{4}$ As ideias constantes desse tópico foram desenvolvidas, em uma primeira versão, em Dutra (2012). 
especulação, sem compromisso com as capacidades produtivas, da qual decorreu o endividamento dos países de capitalismo periférico (DELGADO, 2015, p. 13-27).

Somaram-se a isso a hegemonização de um pensamento econômico orientador das políticas dos Estados, que se intitulou neoliberalismo; a ascensão de lideranças políticas neoliberais em países ocidentais de destaque (Margaret Thatcher na Inglaterra, Ronald Reagan nos EUA, Kohl na Alemanha); e a ausência do contraponto político à maximização ideal do bloco capitalista, decorrente da queda do bloco soviético (DELGADO, 2015, p. 13-27).

A Terceira Revolução Industrial, com mecanização e robotização intensivas, compõe esse cenário, reduzindo drasticamente os postos de trabalho. Paralelamente, o modelo fordista de produção é superado por diversas técnicas produtivas, destacadamente o toyotismo, que trouxe a lógica de empresas enxutas, com cadeias produtivas horizontalizadas, largo uso da força de trabalho terceirizada e produção na medida da demanda (just in time), além de um forte apelo por flexibilidade (DELGADO, 2012, p. 163-182).

Harvey apresentou como fatores da transição do modelo fordista para o modelo just in time de produção, destacadamente, o surgimento de uma organização horizontalizada do trabalho, um forte apelo por desregulamentação e flexibilidade e a categorização dos trabalhadores em dois grupos: um grupo central, composto por trabalhadores qualificados e detentores de empregos formais e estáveis, e um grupo periférico, composto por terceirizados, temporários, autônomos e subcontratados em geral, que prestariam serviços sem segurança no posto de trabalho e em condições precárias (HARVEY, 2003, p. 167-169).

O novo modelo toyotista de produção, além de promover um enxugamento dos quadros de trabalhadores, se prestou a atuar sobre a subjetividade dos trabalhadores, eis que representou a transferência do controle da produtividade e da qualidade para pequenas equipes de trabalho, agora remuneradas pessoalmente, a partir dos resultados alcançados, com intensificação do ritmo de trabalho. A larga utilização do trabalho em equipe, envolvida com valores motivacionais, representou a horizontalização do controle da produção (ALVES, 2011).

De outro lado, a ideia de desenvolvimento de trabalhadores polivalentes, aptos a exercer diversas funções (controlando várias e não mais apenas uma máquina, como ocorria no fordismo/taylorismo) revelou a intensificação do ritmo de trabalho, visto que, dentro da mesma jornada ou até em jornadas mais reduzidas, o trabalhador se ativava em diversas funções. A organização toyotista se vale, para tanto, da tomada de compromisso de cada um dos trabalhadores - a qual, em regra, é forjada pelo medo de perder o emprego - e da extração de todas as suas potencialidades e habilidades para o trabalho em favor da reprodução capitalista (ALVES, 2011).

O discurso da motivação em favor da empresa, que se transformou numa nova ética para o trabalho, é acompanhado de um discurso para a vida dos 
trabalhadores: a exacerbação do individualismo faz com que cada um se torne responsável pelo seu sucesso ou seu fracasso, que será mera consequência dos esforços empreendidos. Assim, a remuneração por produção, o envolvimento e disposição absoluta para o capital como condição para promoções e para garantia do emprego revelam que cada um, e não a voracidade do sistema capitalista, é responsável por sua graça e por sua desgraça. Vencedores e perdedores se separam, inclusive na (im)possibilidade de desenvolvimento de vínculo de solidariedade, a partir das suas qualidades e empenhos individuais. O que prevalece, nessa lógica, é a competitividade e o individualismo.

O padrão toyotista, longe de mecanizar o trabalhador, desejava a participação ativa da sua inteligência e da sua habilidade, desde que apropriáveis pela dinâmica da reprodução capitalista (ALVES, 2011): não bastava mais colher o tempo do trabalhador por jornadas extenuantes, exigindo do seu corpo até o limite da exaustão. $\mathrm{O}$ referido modelo produtivo pretendia, além dessa dimensão do trabalho, o comprometimento psicológico dos obreiros, que deveriam "vestir a camisa da empresa", trabalhar durante toda a jornada sem "tempos mortos", num ritmo intenso, comprometendo-se com os resultados, fiscalizando a si e aos demais colegas (ALVES, 2011).

Nesse processo, a afirmação da identidade coletiva dos obreiros foi minada de modo decisivo, na medida em que a coletivização da produção e o estabelecimento de vínculos de solidariedade foram substituídos pelo individualismo e pela competição, que transforma trabalhadores alocados lado a lado na empresa em adversários, seja porque são divididos em categorias (centrais e precários), cujos empregos são reciprocamente ameaçados uns pela existência dos outros, seja porque precisam esforçar-se individualmente, independentemente das eventuais dificuldades dos demais, para alcançarem resultados pré-definidos.

A afirmação da identidade individual, que não se desvincula dessa identidade coletiva, ainda que se efetivasse com relação aos funcionários centrais, se fazia por meio de uma apropriação tão intensa pelo capital, que subvertia os limites mesmo do trabalho alienado, a ponto de gerar o adoecimento psíquico da classe obreira.

O tempo livre cada vez mais passou a ser demandado para o desenvolvimento, por conta dos trabalhadores, de atividades de aperfeiçoamento profissional (resultado do discurso difundido de que o sucesso de cada um, no trabalho, só depende dos esforços envidados) ou para o consumo vazio. Essa construção identitária deturpada (que alcança os poucos trabalhadores centrais, porquanto os trabalhadores periféricos, à míngua de reconhecimento, sequer conseguem se afirmar pelo trabalho) tem sido a raiz de um profundo adoecimento da classe obreira.

As chamadas doenças da alma, presentes na medida em que se afirma o "vazio ontológico", tem crescido em larga escala, ocasionando picos de stress, focos de depressão, alcoolismo, síndrome do pânico, síndrome de burnout (GRANGEIRO; 
ALENCAR; BARRETO, 2008) e, em mais casos do que os noticiários permitem conhecer, suicídios 5 .

Mészáros (2011) enuncia a contradição: um dos traços mais paradoxais desse novo complexo de reestruturação produtiva do capital é ativar, por um lado, intensos dispositivos de envolvimento estimulado do trabalho vivo com a lógica da produção do capital e, por outro lado, transformar uma proporção cada vez maior de "trabalho vivo" em força de trabalho supérflua do ponto de vista do capital.

$\mathrm{Na}$ análise de Giovanni Alves, a rede informacional oriunda do que se denominou Quarta Revolução Tecnológica ${ }^{6}$, é uma rede controlativa, que atua na captura da subjetividade dos trabalhadores. O autor se reporta a um controle sociometabólico pelo capital, que não se restringe mais ao espaço da relação de emprego, mas invade o lazer e a casa dos trabalhadores. O novo nexo psicofísico com o trabalho teria duas faces diversas: a captura da subjetividade no trabalho e a extensão de valores da produção para a vida, acarretando o que se denomina eticidade do econômico (ALVES, 2011, p. 70-71).

Alves identifica três mecanismos do processo de captura da subjetividade dos trabalhadores pelo capital: as novas formas de pagamento (pagamento por produtividade, de bônus produtividade e de participação nos lucros e resultados), as equipes de trabalho (representativas da difusão do controle do empregador) e o engajamento estimulado (que se traduz na apropriação dos valores subjetivos dos trabalhadores em prol da reprodução capitalista) (ALVES, 2011, p. 120).

Por outro lado, a extensão de valores da produção para a vida, acarretando o que se denominou eticidade do econômico, faz com que os valores cobiçados em um trabalhador ideal do modelo de produção toyotista sejam lançados como ideal para a vida. O discurso da competência e do empreendedorismo revela-se como inovação sociometabólica do capital que manipula os trabalhadores dentro e fora do trabalho. O tempo de trabalho agora também é o tempo de não trabalho (ALVES, 2011, p. 93) o discurso das empresas torna-se um discurso para a vida (ALVES, 2011, p. 94-95).

Mais recentemente, esse conjunto de transformações vivenciado no mundo do trabalho se potencializou, observando o mesmo vetor precarizante, com o que Ricardo Antunes denomina de ascensão da ciberindustria ou indústria 4.0 (2018).

A chamada quarta revolução industrial se caracteriza pelo manejo de redes inteligentes aptas a programar e interconectar processos produtivos inteiros, com a construção das chamadas fábricas inteligentes, que envolvem inteligência artificial, Internet das Coisas, nanotecnologia, biotecnologia, dentre outros recursos que

${ }^{5} \mathrm{O}$ denominado karoshi no Japão é uma realidade que já se aproxima das fábricas brasileiras e que já é enfrentada em outros países, conforme revelam os estudos de Dejours (2006).

" A Quarta Revolução Tecnológica ou "Quarta Idade da Máquina" é definida por Giovanni Alves (2011) como a "revolução das redes informacionais", desdobramento da Terceira Revolução Tecnológica, que consistiria na "revolução informática". (ALVES, 2011, p. 70-71) 
radicalizam os avanços da terceira revolução industrial, numa velocidade alarmante (SCHWAB, 2016.).

A partir de uma radicalização da lógica produtiva instaurada desde 1970, as tecnologias de comunicação e informação estariam a informatizar os processos produtivos, eliminando postos clássicos de trabalho, mas, concomitantemente, alimentando uma periferia precária que, segundo Antunes, é face da mesma moeda (ANTUNES, 2018).

Uma dimensão importante desse processo de transformação do lugar do setor industrial nas economias dos países, tendo como contrapartida o crescimento significativo do setor de serviços, cujo acesso à população é cada vez mais facilitado pelas novas tecnologias, é a difusão daquilo que se tem denominado de Gig economy (ou "economia dos bicos"), economia do compartilhamento e work on demand (ABÍLIO, 2019).

As chamadas empresas-plataformas gerenciam transações relativas à prestação dos mais diversos tipos de serviços, ocultando, por meio dos comandos estabelecidos unilateralmente nos algoritmos dos aplicativos, a sua ingerência, poder e controle sobre os trabalhadores que subordinam (ABÍLIO, 2019). Esses são recrutados sob o discurso do empreendedorismo e da autonomia, que se apresenta como faceta radicalizada da captura da subjetividade dos trabalhadores no modelo toyotista: o movimento manipulatório do capitalismo se tornou tão eficiente que, instrumentalizando as inovações tecnológicas, é capaz de engajar trabalhadores, exatamente conforme os seus interesses, prioridades e diretrizes ao mesmo tempo em que os afirma como autônomos e que se afasta de toda e qualquer responsabilidade decorrente da atividade econômica exercida. Trata-se de uma "autonomia administrada por sofisticados sistemas de controle de qualidade" (ABÍLIO, 2019, p.20).

Como explica Abílio, as empresas-plataformas lançam mão da uberização como forma de transferir os riscos da atividade econômica aos trabalhadores e até mesmo o gerenciamento (nos moldes por elas desejado) aos próprios empregados, por meio de estratégias como a "gamificação" (estratégia de gestão por meio da qual a produtividade dos trabalhadores é estimulada e conquistada por meio de regras impostas unilateralmente pelos aplicativos, que se apresentam como desafios, envolvem premiações e fundam-se na incerteza de se alcançar o resultado perseguido), da consolidação do trabalhador como um "trabalhador just-in-time" (aquele que encontra-se à disposição da empresa, sem ter clareza ou controle sobre a forma como seu trabalho é disponibilizado e remunerado) e do manejo do empreendedorismo como novo modo de subjetivação (ABÍLIO, 2019).

Dessa forma, assim como os elementos produtivos básicos à própria indústria 4.0 estariam a ser extraídos da periferia (países do sul) em condições gravosamente precárias, o mesmo processo de informatização das relações estaria a alimentar o surgimento de postos de trabalho em um setor de serviços composto pelo que denomina "intermitentes globais": trabalhadores que, para fugir do desemprego, 
colocam-se em situação de permanente disponibilidade para, sob o manto do empreendedorismo, fruírem do "privilégio da servidão" (ANTUNES, 2018).

Entre eles, estão os trabalhadores de entrega de mercadorias por meio de aplicativos. Representados por uma radicalização do conjunto de valores que amparou o ideário pós-fordista, esse grupo é conformado pelo cenário do desemprego e pela dimensão ideológica do empreendedorismo, sob o manto da qual se praticam condições de trabalho já reputadas inaceitáveis no bojo de relações de emprego subordinadas.

\section{AS RELAÇÕES INTERMEDIADAS PELOS APLICATIVOS DE ENTREGA DE MERCADORIAS E O DIREITO FUNDAMENTAL AO TRABALHO DIGNO: O DESCAMINHO DA UBERIZAÇÃO}

Não se pode negar que, diante do aprofundamento da crise econômica no Brasil e da eliminação das vagas formais de emprego, os aplicativos como Uber, iFood e Rappi se tornaram importantes na oferta de trabalho, atraindo grande parte do contingente de desempregados do Brasil. As atividades exercidas por meio dos aplicativos, a despeito de se apresentarem como oportunidade de renda extra para alguns trabalhadores, rapidamente passaram a ser o principal meio de sustento de uma parcela significativa da população, mudança que gera diversas consequências trabalhistas e previdenciárias para este grupo que cresce a cada dia.

De acordo com a pesquisa do Instituto Locomotiva, aplicativos como Uber, iFood e Rappi seriam os maiores "fornecedores de trabalho" brasileiros caso se unissem em uma única companhia, vez que estes, conjuntamente, possuem cerca de 5,5 milhões de prestadores de serviços vinculados à suas plataformas ${ }^{7}$.

A ascensão desses serviços de entrega é apoiada em uma lógica de precarização do trabalho, sendo necessário criar estratégias mercadológicas e de marketing para este processo se tornar mais aceitável perante a sociedade e o mercado consumidor (TECNOCRACIA, 2019). Neste sentido, é que começou a ser realizado o discurso do empreendedorismo, do homem-máquina, associando a imagem do entregador a um empresário, que supostamente faz o seu horário de trabalho e lucra de acordo com a sua produtividade.

Os aplicativos de entrega, propositalmente, ocultam do seu modelo de negócios a subordinação clássica entre o entregador e o aplicativo, de modo que este último supostamente não teria "chefe", possuiria a "liberdade" para aceitar ou negar entregas, flexibilidade do horário de trabalho e remuneração por produtividade, passando a ser enquadrado como autônomo, e não como empregado.

De fato, não existe um chefe direto que ordene as entregas e defina o horário de trabalho dos entregadores, mas existe uma "mão invisível" que coordena toda a

\footnotetext{
${ }^{7}$ Conforme os dados divulgados na Revista Exame, em 2018 só nas regiões metropolitanas, 18 milhões de brasileiros usaram regularmente aplicativos para ganhar algum dinheiro, conforme o levantamento realizado pelo Instituto de Pesquisas Locomotiva para a Exame, sendo que dentre esses 18 milhões, 5,5 milhões são cadastrados como prestadores de serviços em plataformas como Uber, 99, iFood, e Rappi. (OLIVEIRA et al, 2019, p. 18)
} 
atividade: o algoritmo do aplicativo. Isto é, a inteligência e os dados regem o fluxo de entregas, logística de pagamentos, gorjetas, avaliações e penalidades (MATSU, 2019).

Então, toda a organização das empresas-aplicativos de entrega não se funda em um modelo de negócios tradicional - em que há a necessidade de uma subordinação direta entre um chefe e empregados - mas sim em um novo arranjo no qual os comandos e penalidades partem de resultados de algoritmos. Ao invés de criar um sistema de cargos e de chefia para controlar os trabalhadores, a tecnologia permite a realização do mapeamento do trabalho de milhares de pessoas, ao mesmo tempo, cruzando os dados de demanda, tempo de entrega e avaliação dos consumidores (MATSU, 2019).

A remuneração baixíssima realizada por produção, por exemplo, é uma forma de criar jornadas extenuantes, além do limite constitucional, pelo entregador que necessita de determinada quantia para sustentar a sua família (SABINO; ABÍLIO, 2019). Assim, a dependência do entregador e a remuneração realizada por produção possibilitam que os entregadores fiquem mais tempo à disposição do serviço.

Outra forma de controle dos entregadores feita através do algoritmo são as avaliações dos clientes, que funcionam como um gerente coletivo, atribuindo notas, comentários (ABÍLIO, 2017). Em sendo realizada alguma denúncia por máconduta, caso o entregador não aceite determinado número de entregas ou se manifeste contra a empresa, o aplicativo pode sancionar o trabalhador através de bloqueio permanente ou temporário de plataforma, o que se equipararia a uma espécie de punição e até mesmo rescisão contratual (ABÍLIO, 2019).

Além disso, os entregadores são obrigados a manter o preço estipulado pelo aplicativo, não formam clientela fixa e aceitam entregas em trajetos já estipulados pelo aplicativo, elementos que afastam o caráter de autônomo atribuído a estes pelos aplicativos (WESCHENFELDER, 2019).

Logo, o modelo de negócios dos aplicativos-empresas de entregas se funda no uso do algoritmo e da tecnologia para realizar funções outrora desempenhadas pelos superiores hierárquicos. O controle do fluxo de trabalho, de satisfação do cliente e quantidade de entregas feito pelo algoritmo possibilita a realização do controle e punição dos entregadores, elementos que ensejam uma nova forma de subordinação.

O ponto nevrálgico da questão atinente a essa nova massa de intermitentes digitais (ANTUNES, 2018) é a dignidade das relações de "não-emprego" criadas pelo modelo de negócios dos aplicativos de entrega, que, supostamente, se limitam a intermediar a relação entre o usuário-cliente e o usuário-entregador.

Diante do imperativo constitucional de que a atividade laboral proporcione a mínima dignidade ao trabalhador, tem-se que o direito fundamental ao trabalho não pode ser entendido como um fim em si mesmo, mas como um plexo de direitos que garantem a dignidade mínima da atividade laboral. 
Em outras palavras, conforme afirma Vilhena, deve-se privilegiar a valorização e tutela da pessoa do trabalhador, ao invés de focalizar apenas na proteção jurídica do trabalho economicamente tutelado (VILHENA, 2000, p. 252-253). Neste sentido, desponta a ideia do direito fundamental ao trabalho digno, e o seu correspondente tensionamento nos momentos de crise.

\subsection{0 direito fundamental ao trabalho digno}

O conteúdo do direito fundamental ao trabalho digno, a partir da construção de Gabriela Neves Delgado, nasce da premissa de que o trabalho, enquanto direito fundamental, deve pautar-se na dignidade humana, sendo esta o nexo existente entre direitos fundamentais e o Estado Democrático de Direito (DELGADO, 2012, p. 183).

Para Gabriela Delgado, no momento que os direitos fundamentais ingressam no ordenamento jurídico, eles devem ser compreendidos enquanto direitos de indisponibilidade absoluta, uma vez que são inatos aos seres humanos (DELGADO, 2012, p. 183). Nesta senda, o direito fundamental ao trabalho digno deve ser uma regra prevalecente no âmbito do Direito do Trabalho brasileiro, sendo este, por sua vez, assegurado por meio de um feixe de direitos trabalhistas que garantem o patamar civilizatório mínimo (DELGADO, 2012, p. 188).

Este feixe de direitos é constituído por basicamente três eixos de proteção: o de amplitude universal (direitos trabalhistas estabelecidos pelos Tratados e Convenções internacionais ratificados pelo Brasil), o de previsão constitucional e, por fim, a proteção infraconstitucional (realizada principalmente pela Consolidação das Leis do Trabalho). Logo, para que o direito ao trabalho digno seja assegurado, é necessário que a atividade seja devidamente regulamentada e que sobre esta incidam as normas internacionais, constitucionais e infraconstitucionais, garantindo o direito à remuneração que promova a subsistência do trabalhador e sua família, o direito à segurança e higiene no trabalho, a proteção ao trabalho e emprego, a limitação razoável das horas de trabalho, entre outros.

Em caminho oposto ao das reformas no direito do trabalho recentemente editadas, tais como a Lei 13.467/2017, a Medida Provisória no 881/2019 (convertida na Lei no 13.874/2019) e a Medida Provisória no 905/2019, nas quais ocorre a exaltação da autonomia privada nas relações de trabalho, entende-se que o Estado Democrático de Direito deve proteger e preservar o trabalho digno por meio da regulamentação jurídica (DELGADO, 2012, p. 184). Há uma verdadeira expectativa de regulamentação de toda e qualquer relação de trabalho, para que, só assim, através da universalização da proteção direcionada pelo direito do trabalho, se garanta a dignidade dos trabalhadores.

O direito a um trabalho protegido e devidamente regulamentado é o mínimo que pode assegurar o trabalho digno (DELGADO, 2012, p. 190). Logo, com o advento destas novas tecnologias faz-se imprescindível repensar a natureza das relações estabelecidas a partir dos aplicativos, para de algum modo abarcar os 
trabalhadores que se encontram nesta nova situação jurídica, criada pelos rearranjos das formas de produção e modelos negociais. Necessário reler o direito do trabalho e a própria realidade social implicada no fenômeno, a fim de reconhecer a esses trabalhadores direitos básicos como igualdade no trabalho, saúde e segurança, patamar mínimo representado pelo conceito de trabalho decente, nos termos de José Cláudio Monteiro de Brito Filho (BRITO FILHO, 2004, p. 61).

Neste mesmo sentido a Organização Internacional do trabalho, atribui um caráter abrangente ao Direito Fundamental ao trabalho decente, o qual passa por diversos campos, como remuneração, segurança do trabalho, desenvolvimento pessoal e integração. Assim, ao tratar sobre o tema este órgão afirma:

O conceito de trabalho digno resume as aspirações de homens e mulheres no domínio profissional e abrange vários elementos: oportunidades para realizar um trabalho produtivo com uma remuneração justa; segurança no local de trabalho e proteção social para as famílias; melhores perspectivas de desenvolvimento pessoal e integração social; liberdade para expressar as suas preocupações; organização e participação nas decisões que afetam as suas vidas; e igualdade de oportunidades e de tratamento (OIT, 2018).

Logo, para a Organização Internacional do Trabalho, a atividade laboral não deve apenas promover a subsistência do trabalhador, como também garantir a liberdade, possibilitar a proteção social para as suas famílias e melhores perspectivas de desenvolvimento pessoal. Inclusive, para efetivar o conceito de trabalho decente, este órgão possui agendas e metas, incluindo o Brasil e a América Latina neste objetivo.

É certo que a ordem econômica brasileira, além de valorizar o trabalho prevê a livre iniciativa no art. 170 da Constituição Federal. Contudo, o poder diretivo dos empregadores é limitado pelo cerco da dignidade da pessoa humana e pelas normas trabalhistas internacionais constitucionais e infraconstitucionais.

Considerando as condições de trabalho, nota-se que, apesar de os aplicativos de entrega como UberEats, Rappi, iFood movimentarem a economia e a proporcionarem a geração de renda, estes não promovem o trabalho digno, uma vez que sobre estas relações, tal como conformadas pelos aplicativos de entregas, não incidem diversas regras fundamentais para a garantia do patamar civilizatório mínimo, tais como a de limitação razoável das horas de labor e a promoção da segurança e higiene do trabalho.

A ausência de regras trabalhistas que resguardem a relação entre os "usuáriosentregadores" e os aplicativos já vem causando diversos acidentes de trabalho, seja pelo excesso de horas de trabalho, ausência de equipamentos de proteção ou 
estresse gerado pelo excesso de entregas ${ }^{8}$. Vive-se um cenário de verdadeira precarização do mundo do trabalho caracterizado não mais pelo emprego em condições precárias, como se observava anteriormente, mas sim, pela tentativa de burlar a existência da própria relação de emprego, negando ao trabalhador a condição de empregado através de contratos de parceria, fomento ao empreendedorismo, falso associativismo, entre outros.

Neste ponto, cumpre destacar que a ordem jurídica brasileira infraconstitucional cria patamares distintos de proteção entre as relações de trabalho, sendo a maior proteção destinada à relação de emprego, ao tempo em que atenua sua tutela quanto às relações trabalhistas lato sensu (DELGADO, 2012, p. 190). Assim, na mesma medida em que o direito do trabalho inclui e protege, ele atenua o rol de direitos dos trabalhadores inseridos em relações não empregatícias, o que, entretanto, não significa dizer que essas relações estejam desprotegidas por completo ou infensas à tutela da dignidade da pessoa humana. Também é válido registrar que, para autores como Noemia Porto (2013) essa perspectiva restritiva não seria amparada pelo Texto Constitucional, o qual, ao se referir aos direitos sociais trabalhistas, elege a terminologia trabalhadores, e não empregados.

Entretanto, tendo em vista o pensamento majoritário, cujo marco é a própria regulamentação trabalhista, muitos negócios são pensados de modo a mascarar os requisitos clássicos da relação de emprego - principalmente a subordinação -, cenário que não é novo no contexto brasileiro, em que se tem uma presença significativa de fraudes trabalhistas delineando o campo da informalidade laboral.

Ocorre que o que se observa em relação aos aplicativos de entrega é um verdadeiro exército de pessoas que, apesar de prestarem serviços para terceiros em troca de sua subsistência de forma estruturalmente subordinada, ainda assim não são consideradas empregadas nem mesmo reconhecidas como trabalhadoras lato sensu para efeitos protetivos, uma vez que sequer as noções civilistas de operabilidade, socialidade, boa-fé e lealdade contratual são observadas em relação aos supostos trabalhadores autônomos, regidos e avaliados por critérios desconhecidos, unilaterais e, muitas vezes, arbitrários.

Por consequência, estas pessoas têm afastada de si a possibilidade de fruição de qualquer dimensão do direito fundamental ao trabalho digno, inclusive em sua faceta atenuada. Nessa esteira, o trabalhador, supostamente, deixa de ser aquele que aliena sua força de trabalho em troca de salário, subordinando-a ao empregador, nem sequer usufrui das proteções típicas do trabalho autônomo, mas apresenta-se como um empreendedor/parceiro, que possui uma jornada de trabalho flexível e arca com os riscos da atividade, inclusive no que diz respeito à saúde e segurança do trabalho e cuja principal afirmação identitária não é sua condição profissional, cidadã ou a titularidade de direitos, mas sim o credenciamento de um perfil em uma plataforma digital, conforme critérios, condições e prazos que sejam convenientes à própria empresa-plataforma.

${ }^{8}$ Sobre esta questão ver Farah (2019), Estadão conteúdo (2019) e Borges(2019). 


\section{OS SUJEITOS DO DIREITO DO TRABALHO: CRISE?}

A problemática trazida pelos aplicativos se ampara fortemente no discurso do empreendedorismo, do homem-empresa, do uso da tecnologia como forma de mascarar a materialidade das relações de trabalho, sua subordinação e dependência, bem como os elementos de poder e exploração ali envolvidos.

Esse aparato discursivo envolve, em grande medida, a negação do emprego, por meio da recusa do reconhecimento dos elementos fático jurídicos da pessoalidade, não eventualidade, subordinação jurídica e onerosidade da prestação de serviços, mas alcança até mesmo o reconhecimento de uma relação de trabalho em sentido lato, na medida em que se colocam os aplicativos, num primeiro momento, como mediadores da relação entre prestadores e beneficiários dos serviços, os quais, em relação às plataformas, se materializariam igualmente enquanto consumidores dos serviços oferecidos pela plataforma digital. Mesmo quando, num segundo momento, o discurso das plataformas em relação aos trabalhadores passa a considerá-los autônomos, essas figuras são colocadas de forma alheia às regulamentações já disponíveis na legislação para outros trabalhadores autônomos (como motoristas profissionais, representantes comerciais, trabalhadores em salões de beleza, entre outros).

Se as disputas sobre o vínculo empregatício têm feito parte do repertório do capital para refugar a regência do direito do trabalho desde seus primórdios, acentuando-se a partir da reestruturação produtiva e da heterogeneização das formas de contratação, a negação da condição de trabalhador, com pretensão de deslocamento do debate para fora da seara mais ampla da prestação de serviços e da negociação da força de trabalho pelos próprios sujeitos envolvidos, é disruptiva.

O avanço produzido na seara constitucional, no sentido de proteger trabalhadores, e não apenas empregados, alargando o guarda-chuva de proteção social, como bem observa Noemia Porto, havia reavivado o debate sobre a tendência expansionista do direito do trabalho e sua possibilidade de abarcar a proteção para além da seara do emprego (PORTO, 2013). Todavia, o horizonte constitucional tem sido esgarçado pelas reformas neoliberais e pelas flexibilizações jurisprudenciais, de modo a comprometer essa perspectiva decisivamente.

Para além desse cenário, os novos arranjos produtivos têm deslocado ainda mais a discussão a partir da negação de qualquer envoltório trabalhista para a pactuação que operacionaliza os aplicativos de entrega de mercadorias: como peculiar à semântica de guerra híbrida, a discussão sobre eventual extensão dos direitos é afastada em favor de perguntas prévias e impeditivas das subsequentes: é a maior empresa de transportes do mundo uma empresa de transportes ou apenas uma plataforma digital? Os motoristas a serviço de uma empresa de transportes e os trabalhadores a serviço de uma empresa de entregas são trabalhadores explorados por elas ou apenas beneficiários de seu serviço de logística? Há um conflito entre capital e trabalho ou apenas relações de cooperação e associação entre empreendedores da tecnologia e empreendedores do transporte e das entregas? 
As últimas perguntas obnubilam eficazmente as perguntas objetivas a serem feitas diante de um sujeito de direitos trabalhistas: Qual o limite de jornada? Qual o rendimento mínimo do trabalho? Quem assume os riscos da atividade econômica? Como se concretiza a prevenção em matéria de saúde e segurança do trabalho? Qual arranjo permite a representação sindical dos grupos envolvidos para concretização do diálogo social?

A discussão remonta ao próprio reconhecimento do conjunto de trabalhadores envolvidos enquanto coletivo e sua aptidão para reivindicar direitos. Antunes tem tratado dos desafios para a compreensão dessas novas frações e grupos como parte da metamorfoseada e heterogênea classe trabalhadora no século XXI (ANTUNES, 2018).

Nesse sentido, a reflexão de Pedro Nicoli, que aponta que o reconhecimento coletivo do polo trabalhista enquanto grupo que resiste à exploração é o pressuposto para, a partir dessa potência de resistir, constituir identidade e delinear um processo que permita a afirmação do estatuto social de trabalhador, enquanto sujeito de direitos (NICOLI, 2016).

Nicoli observa que é produto da modernidade a densidade conceitual do sujeito de direitos e a sua pretensão de universalidade social. A ascensão do capitalismo e sua explosão no contexto da Revolução Industrial permitiram que a desumanização vivida pelos trabalhadores animasse um sujeito coletivo resistente, a fomentar o surgimento de legislação fabril que afirmasse cada um dos sujeitos como sujeito de direito. Assim, para o autor, é "na chave dos trabalhadores como pessoas dentro do direito que o ramo justrabalhista se constrói", já se aproximando das concepções contemporâneas de sujeito de direito (NICOLI, 2016, p. 20).

Tanto na matriz hegeliana, como na perspectiva marxista, as diferentes leituras sobre o sujeito de direito adquirem relevância central para compreender a sociedade capitalista.

Como sintetiza Kashiura Jr., para Hegel, na sociedade capitalista, em oposição a outras racionalidades que a precederam, é a capacidade de ser proprietário, na qual se inclui a capacidade de ser proprietário de si, que define o sujeito de direito. Contraditoriamente, seria a elevação do ser humano à condição de sujeito de direito que o habilitaria, em um ato de vontade, a reduzir-se à condição de coisa. Para o autor, "a universalização da personalidade jurídica se realiza, ao mesmo tempo, como universalização da coisificação do homem, da redução de si próprio às determinações da propriedade" (KASHIURA JR, 2014, p. 124).

A partir da perspectiva hegeliana, depreende-se o esforço de compatibilizar a condição de liberdade do sujeito com sua passibilidade de objetivação. Nesse sentido, Hegel sustenta que a inadmissibilidade da restrição de liberdade do corpo do sujeito "para os outros" não vale para ele mesmo (KASHIURA JR, 2014, p. 126.), daí porque a possibilidade de negociar sua própria força de trabalho. Outro aspecto importante para tal compatibilização seria, na visão de Hegel, a limitação temporal da disponibilização da força de trabalho do indivíduo para o outro: 
A condição para que o sujeito de direito possa manter-se como tal ao alienar a si mesmo é que essa alienação seja parcial, quantitativamente limitada. (...) O homem só pode alienar-se como coisa porque é livre, isto é, sujeito de direito. Por sua vontade livre, apenas por meio dela, torna-se proprietário de si. E só o que o separa da completa aniquilação pela liberdade - ou seja, da completa aniquilação da sua condição de sujeito - é uma certa medida de tempo (KASHIURA JR, 2014, p. 130).

Mas à frente, o autor indica que "esse relógio é, no fim das contas, o relógio de ponto da fábrica” (KASHIURA JR, 2014, p. 130). Na visão idealista de Hegel, estão, portanto, firmadas como pressuposto da condição filosófica de sujeito de direito a liberdade de decidir sobre sua própria existência e trabalho, assim como a limitação desse comprometimento da força de trabalho que, historicamente, se concretiza não por meio da previsão individualista de limitações temporais dentro de cada contrato de trabalho, mas sim por meio de uma legislação do trabalho impositiva de limites de jornada, bem como de diversos outros limites que conformem a ideia de "alienação parcial, quantitativamente limitada" da força de trabalho.

$\mathrm{Na}$ percepção de Kashiura Jr, a obra de Hegel traria a contribuição de reconhecer "inversões desconcertantes" da sociedade moderna que se perpetuam na base da personalidade jurídica:

A distribuição desigual da propriedade mediada pela igual capacidade para ser proprietário, a coisificação do trabalho assalariado mediada por uma liberdade temporalmente excepcional, a possibilidade de realização da dependência através da vontade livre e da personalidade jurídica (KASHIURA JR, 2014, p. 158).

A perspectiva materialista, definidora da obra de Marx e desenvolvida no campo jurídico por Pachukanis, inverte a perspectiva trazida por Hegel, ao reconhecer que a forma mercadoria é a forma jurídica essencial ao funcionamento da dinâmica de trocas de uma sociedade capitalista. Ela implicaria a subsunção do trabalho ao capital, na medida que o valor abstrato das mercadorias representaria o valor do trabalho abstrato nela cristalizado e revelaria a vinculação fundamental entre o sujeito de direito e o processo de troca de mercadoria (KASHIURA JR, 2014, p. 162-164).

A crítica marxista, impiedosa com a figura do sujeito de direito tão cara à teoria dos direitos fundamentais e com suas contradições, tende a entende-la como mera representação formal do núcleo de vontade necessário à concretização das trocas de mercadoria e, apreendendo-a como invólucro formal capaz de, sob os pretextos 
formais da igualdade e da liberdade (essenciais às trocas comerciais e à circulação da forma-mercadoria), fazer "desaparecer a diversidade natural e social dos trocadores do mesmo modo como a forma mercadoria faz desaparecer a dimensão útil e diversa das coisas que são trocadas" (KASHIURA JR, 2014, p. 171).

Sob o capitalismo, a generalização do sujeito de direito teria tão-somente o condão de, contraditoriamente, converter em proprietário de si mesmo aquele que é expropriado dos meios de produção. Diferentemente de Hegel, que via nesse binômio igualdade dos sujeitos de direito e desigualdade econômica uma contradição, Marx entenderá que a desigualdade na propriedade e universalização do sujeito de direito integra um mesmo movimento inerente ao funcionamento da sociedade capitalista (KASHIURA JR, 2014, p. 188), que determina a submissão do trabalho ao capital. Em Marx, o ser humano é alçado a sujeito de direito exatamente porque reduzido à forma mercadoria por meio do trabalho livre (KASHIURA JR, 2014, p. 191).

Mas, na exata esteira de Hegel, também Marx apontará que a expressão subjetiva da troca de mercadoria só fica assegurada se, na troca da força de trabalho por salário, o vendedor não ceder a integralidade do seu tempo ao comprador, o fazendo por tempo determinado (KASHIURA JR, 2014, p. 209), de modo que a alienação da mercadoria força de trabalho permita preservar de posse do trabalhador ainda uma parcela de tempo não alienado.

Fica evidente que, para as duas concepções distintas acima visitadas, o caráter limitado da disposição do tempo era constitutivo da figura do sujeito de direitos. A relevância do resgate da contribuição dos dois filósofos, que certamente lançam luzes sobre as origens da significação das formas jurídicas básicas, reside em observar que o desenvolvimento do campo jurídico e a complexificação das relações sociais e políticas verte sobre o sujeito de direito, originalmente pensado de modo instrumental, novas projeções e horizontes que se traduzem em compromissos políticos e jurídicos cada vez mais amplos. Ou seja, para além dos contornos mínimos da limitação da disponibilidade temporal da força de trabalho pelos sujeitos, a titularidade de direitos se expande para diversas searas de proteção da pessoa humana.

Nesse sentido, ressalta-se o próprio desenvolvimento e institucionalização do direito do trabalho, enquanto contramovimento limitador dos mecanismos predatórios do capitalismo (POLANYI, 2011), assim como o aprofundamento de um pensamento ético e humanista reconhecedor de direitos da pessoa humana (DELGADO, 2012) e capaz de negar a premissa material da identificação do trabalho humano com a mercadoria, tal como posto na Declaração de Filadélfia de 1944. Sem se descolar da tendência lancinante do capital a aproximar o sujeito da forma mercadoria, a construção política e humanística do século XIX tensiona e disputa esse projeto em direção a novos paradigmas, tal como a afirmação da titularidade de um direito fundamental ao trabalho digno. 
Se a disputa semântica do campo do direito orienta-se no sentido de atribuir outro lugar - de proteção e dignidade - à pessoa humana que trabalha, requalificando a ideia de sujeito de direito, a disputa regulatória instaurada pelos aplicativos orienta-se pela negação da condição de sujeito de direitos trabalhistas ou mesmo de pessoa - aos motoristas e entregadores, na medida que os aproxima da figura-jurídica empresa e desconsidera toda a compreensão de sujeito de direitos forjada seja a partir da doutrina humanística do século XIX, seja a partir do construto pessoa-mercadoria encontrado em Hegel e Marx. Ali não há sequer espaço para discussão sobre o tempo alienado pela força de trabalho, já que a questão da jornada aparece como questão estranha ao contrato entre aplicativos e trabalhadores.

Numa artificiosa (ou ardilosa) absolutização da ideia de liberdade e autonomia que desumaniza os sujeitos engajados na atividade, a contratação uberizada recusa a esses a condição pessoal de sujeito de direitos: em verdade, é como se a personalidade virtualizada num perfil credenciado junto à plataforma digital se submetesse a um regramento algorítmico variável, unilateral e imprevisível que não devesse nenhuma reverência aos comandos legais que regem as relações trabalhistas ou mesmo as relações civis entre particulares. Trata-se do fenômeno que Carelli denominou de "refeudalização das relações laborais" (CARELLI, 2017), justamente a partir de uma perspectiva de relações de aliança entre sujeitos supostamente livres, que, ao se submeterem intensamente à programação (e não a comandos diretos do empregador), muitas vezes se confundem com os objetos dos contratos, incompatibilizando-se com a figura do sujeito de direitos.

O desafio da reconstrução do sujeito de direitos, a partir do remodelamento das relações produtivas, outrora encampado por Pedro Nicoli, ganha novo sentido a partir da própria negação dessa condição a um determinado grupo de indivíduos trabalhadores (NICOLI, 2016).

A crítica marxista, que observa na figura do sujeito de direitos a representação jurídica do titular da troca da forma-mercadoria, que traduz o trabalho abstrato ali contido (PACHUKANIS, 2017), e a própria problematização da ideia de subordinação a partir de conceito de liberdade dos sujeitos, eis que o pressuposto do direito do trabalho seria também a contraditória legitimação de uma relação de quase sujeição, é assimilada por Nicoli a partir da "aceitação da ambivalência intransponível do sujeito" (NICOLI, 2016, p. 20) : ao mesmo tempo que decorre do exercício de poder legitimado sobre ele, o habilita para resistir a esse poder, porque limitada.

Essa percepção deve ser temperada, primeiro, pelo fato de que a subordinação, diante das transformações da esfera produtiva, passa a significar muito mais a integração do trabalho prestado na estrutura do tomador de serviços; segundo, pelo fato de ainda ostentar potencial inclusivo e emancipatório em face da desfiliação promovida pela falsa autonomia (NICOLI, 2016, p. 46). 
Assim, refuta o autor a contestação da ideia de subordinação jurídica como promessa vazia de aprofundamento da liberdade:

A celebração acrítica das formas de autonomia fora do contrato, sob os horizontes presentes, pode sofrer do esvaziamento que o momento de emergência da liberdade e do sujeito sofreu quando de sua constituição moderna. Se a contemporaneidade se vale da individualização desenfreada, da perda dos laços coletivos e institucionais, das trajetórias, de uma vida puramente biográfica, sujeito e contrato podem contribuir para processos emancipatórios. A subordinação, aí, encarada como critério em novas interpretações, ampliadas, que engajem a responsabilidade da contraparte, reequilibrando um sistema oportunista, que, mais uma vez, parece querer se valer da liberdade como pura forma para tornar o homem menos livre (NICOLI, 2016, p. 49).

Nesse sentido, a capacidade de compreender, diante do metamorfoseamento das relações sociais de produção, novas dimensões do fenômeno subordinativo e de, a partir e para além dele, conceber novas formas de proteção, deve se somar ao resgate de uma compreensão crítica das novas promessas de autonomia e liberdade, de todo vazias de representação na realidade concreta das relações de trabalho pautadas na tecnologia e profundamente precarizadas:

O trajeto percorrido no construir-se do trabalho e dos trabalhadores diante da opressão social revelam que, quanto mais afastados do reconhecimento como valor e como sujeito, mais a reificação tem espaço de legitimação. E se é certo que a fórmula do trabalho subordinado abriga, em larga escala, práticas de sujeição e opressão, a autonomia fora do direito, nos horizontes do capitalismo industrial e de suas estratégias, está ainda muito distante de ser uma alternativa de ampliação das possibilidades de emancipação e igualdade. É preciso transformar, não há dúvida. Mas a transformação deve certamente se dar na continuidade do projeto ético do sujeito, como substancialmente igual, antes de ilusoriamente autônomo (NICOLI, 2016, p. 49).

A defesa do direito do trabalho e da possibilidade do direito fundamental ao trabalho digno passa, portanto, pelo resgate do sujeito de direitos trabalhistas, bem como por sua permanente reconstrução. Para isso, é necessário ter em conta as novas dimensões da subordinação e não abrir mão das conquistas paradigmáticas quanto aos sujeitos de direitos, que não podem ser instrumentalizados ou ocultados pelos avanços tecnológicos. Do contrário, o uso ético e político das inovações tecnológicas deve passar pelo respeito às premissas construídas pelo direito social 
e constitucional, centrado na proteção à pessoa e na sua dignidade, independentemente da natureza das relações laborais celebradas, nem mesmo dos meios pelos quais capital e trabalho se conectam.

\section{CONSIDERAÇÕES FINAIS}

O capitalismo não é único e imutável ao longo da história, mas permanentemente modificável e adaptável no transcurso do tempo, em razão das lutas que o transformaram e das estratégias que o renovaram. Neste cenário de constantes mudanças, surgem os aplicativos de entrega, organizações empresariais com novos modelos de negócios disruptivos, repetíveis e escaláveis, que visam trazer soluções para necessidades diárias (muitas vezes criando necessidades), ou então revolucionar a forma pela qual alguns serviços são prestados.

Sucede que os aplicativos não reconhecem a existência de qualquer vínculo de trabalho com as pessoas que realizam a entrega. Do contrário, afirmam que se limitam a realizar a intermediação entre o usuário-cliente e os motoristascadastrados/entregadores-cadastrados, sem, contudo, assumir qualquer dever ou encargo trabalhista em relação a estes. Assim, o modelo de negócios utilizado por estas empresas busca mascarar o vínculo de trabalho existente entre o aplicativo e o entregador/motorista, sob o argumento de que estes são empreendedores autônomos que apenas se utilizam da plataforma para obter mais clientes.

Diante desta situação, nota-se que as novas formas de labor trazidas pelos aplicativos trazem um desafio para o direito do trabalho que não diz respeito apenas ao trabalho precário, mas, sobretudo, à negação da própria condição de trabalhador e sujeito de direito deste grupo: isto é, não se trata apenas de uma recusa ao caráter subordinado e economicamente dependente dos trabalhadores para efeito do reconhecimento do vínculo empregatício, mas também da própria condição de trabalhador autônomo regulado, com possibilidade de acessar alguma dimensão do direito fundamental ao trabalho digno. Do contrário, as empresasplataforma reduzem a subjetividade do trabalhador à representação por um perfil virtual credenciado numa plataforma digital, inconfundível com a figura do titular de direitos no "plano real", sobretudo ao se esquivar de qualquer tipo de limitação do tempo de trabalho contratado.

Tendo em vista esta questão, o presente artigo buscou discutir as premissas teóricas que deram contornos ao sujeito de direitos trabalhistas na contemporaneidade, a fim de demonstrar como os aplicativos de entrega de mercadorias negam a esses trabalhadores a própria condição de sujeitos de direitos e, por conseguinte, inviabilizam o próprio horizonte do direito fundamental ao trabalho digno.

Entende-se que, diante do metamorfoseamento das relações sociais de produção, novas dimensões do fenômeno subordinativo devem ser admitidas e, a partir e para além delas, deve-se construir a possibilidade de conceber novas formas de proteção para o trabalhador (qualquer que seja a natureza de sua 
vinculação ao beneficiário da prestação de serviços) que se encontram, atualmente, ameaçados pelas novas formas de reprodução capitalista.

\section{REFERÊNCIAS}

ABILIO, Ludmila Costhek. Uberização do trabalho: A subsunção real da viração. Blog da Boitempo. 2017. Disponível em:

$<$ https://blogdaboitempo.com.br/2017/02/22/uberizacao-do-trabalho-subsuncaorealda-viracao/>. Acesso em: 15 out. 2019.

ABILIO, Ludmila Costhek. Uberização do trabalho: Uberização: do empreendedorismo para o autogerenciamento subordinado. Revista Psicoperspectivas: Individuo y sociedad. Vol. 18, n.3, p.1-11, 2019.

ALVES, Giovanni. Trabalho e Subjetividade. São Paulo: Editora Boitempo, 2011.

ANTUNES, Ricardo. Os sentidos do trabalho: ensaio sobre a afirmação e a negação do trabalho. São Paulo: Editora Boitempo, 1999. p. 31-32.

ANTUNES, Ricardo. O privilégio da servidão. São Paulo: Boitempo, 2018.

BORGES, Thais. Até 14 horas de trabalho e $80 \mathrm{~km}$ pedalados por dia: conheça os entregadores por aplicativo. Correio 24 horas. Disponível em https://www.correio24horas.com.br/noticia/nid/ate-14-horas-de-trabalho-e-80-kmpedalados-por-dia-conheca-os-entregadores-por-aplicativo/. Acesso em: 18 ago. 2019

BRASIL. Casa Civil. Medida Provisória no 881 de 2019. Disponível em http://www.planalto.gov.br/ccivil_03/_ato2019-2022/2019/Mpv/mpv881.htm

BRITO FILHO, José Cláudio Monteiro de. Trabalho decente. São Paulo: LTr, 2004.

CARELLI, Rodrigo de Lacerda. O caso Uber e o controle por programação: de carona para o Século XIX. In: CHAVES JÚNIOR, José Eduardo de Resende (Org.). Tecnologias disruptivas e a exploração do trabalho humano. São Paulo: Ltr, 2017.

DARDOT, P.; LAVAL, C. A nova razão do mundo: ensaio sobre a sociedade neoliberal. São Paulo: Editora Boitempo, 2016. 
DELGADO, Gabriela Neves. Direito Fundamental ao Trabalho Digno. E-book: LTr, 2012.

DELGADO, Mauricio Godinho. Capitalismo, trabalho e emprego: entre o paradigma da destruição e os caminhos de reconstrução. Mauricio Godinho Delgado, 2. ed., São Paulo: LTr, 2015.

DUTRA, Renata Queiroz. Direitos fundamentais sociais à afirmação da identidade e à proteção da subjetividade no trabalho. Revista do Tribunal Superior do Trabalho, vol. 78, nº4, out/dez 2012. p 256-287.

ESTADÃO CONTEÚDO. Prefeitura de SP faz acordo com iFood e Loggi para segurança de entregador. Exame. Disponível em:<https://exame.abril.com.br/negocios/prefeitura-de-sp-faz-acordo-com-ifoode-loggi-para-seguranca-de-entregador/>. Acesso em: 18 ago. 2019

FARAH, Tatiana Entregador da Rappi morreu depois de sofrer AVC na porta da cliente. Buzzfeed Brasil. Disponível em:

$<$ https://www.buzzfeed.com/br/tatianafarah/entregador-da-rappi-morreu>. Acesso em: 18 ago. 2019

FERREIRA, António Casimiro. A sociedade de austeridade: Poder, medo e direito do trabalho de exceção. Revisão Crítica de Ciências Sociais, n. 95, 2011.

FILGUEIRAS, Vitor Araújo; PEDREIRA, Sara Costa. Trabalho descartável: as mudanças nas formas de contratação introduzidas pelas reformas trabalhistas no mundo. Cadernos do CEAS: Revista Crítica de Humanidades. Salvador, n. 248, set./dez., p. 578-607, 2019.

FILGUEIRAS, Vitor. Regulação da terceirização e estratégias empresariais: o aprofundamento da lógica desse instrumento de gestão da força de trabalho. Cadernos do CEAS: Revista Crítica de Humanidades, Salvador, n. 239, p. 742-770, 2016.

GAMBA, Juliane Caravieri M. Direito ao trabalho digno e as frentes de trabalho: paradoxos do Estado contemporâneo. Revista do Ministério Público do Trabalho, São Paulo, n. 39, p. 481 - 506, mar. 2010. 
GRANGEIRO, Maria Vanessa T.; ALENCAR, Denyse Torquato de.; BARRETO, Julyanne de O. Paes. A síndrome de burnout: uma revisão da literatura. Revista eletrônica Saúde Coletiva: coletânea, n. 2, nov. 2008. Disponível em: <http://coletanea2008.no.comunidades.net/index.php?pagina=1225285076>. Acesso em: 25 ago. 2012.

HARVEY, David. A Condição Pós-Moderna. São Paulo: Editora Loyola, 2003.

KALLEBERG, Arne L. O Crescimento Do Trabalho Precário: Um Desafio Global. Revista Brasileira De Ciências Sociais, vol. 24, n. 22, p. 21-30, 2009.

KASHIURA JR, Celso Naoto. Sujeito de direito e capitalismo. São Paulo: Outras expressões, 2014.

MATSU, Carlos. Uberização do trabalho e os limites de se trabalhar para um algoritmo. 2019. Disponível em:<https:/computerworld.com.br/2019/07/26/uberizacao-do-trabalho-e-oslimites-de-se-trabalhar-para-um-algoritmo/>. Acesso em: 15 fev. 2020

MÉSZARÓS, István. Para além do capital. São Paulo: Boitempo, 2011.

NICOLI, Pedro Augusto Gravatá. Fundamentos de direito internacional social. São Paulo: LTr, 2016.

OLIVEIRA, Carol; KARIN, Salomão; FONSECA, Mariana; FLACH, Natália. Tudo no Aplicativo. Revista EXAME, n.1183, 17 de abril de 2019. Disponível em:<https://docs.wixstatic.com/ugd/3d9e82_430595dd43b24eecb422a54c4a0f2d9c. pdf>. Acesso em: 21 jul. 2019.

ORGANIZAÇÃO INTERNACIONAL DO TRABALHO (OIT). Trabalho digno. 2018. Disponível em: <https://www.ilo.org/lisbon/temas/WCMS_650867/lang-pt/index.htm>. Acesso em: 17 fev. 2020.

PACHUKANIS, E. Teoria geral do direito e marxismo. São Paulo: Boitempo, 2016.

POLANYI, Karl. A grande transformação: as origens de nossa época. Rio de Janeiro: Elsevier, 2011. 
PORTO, Noemia Aparecida Garcia. O trabalho como categoria constitucional de inclusão. São Paulo: LTR, 2013.

PUTTI, Alexandre. No Brasil em crise profunda, aplicativos como Uber e iFood se tornaram o símbolo dos empregos temporários e mal-remunerados. Carta Capital, 2019. Disponível

em:<https://www.cartacapital.com.br/economia/proletariado-digital-appspromovem-trabalhos-precarios-a-brasileiros/>. Acesso em: 21 jul. 2019

SABINO, André Monici; ABÍLIO, Ludmila Costhek. Uberização - o Empreendedorismo como novo nome para a exploração. Revista Jurídica Trabalho e Desenvolvimento Humano, v. 2, n. 2, dez. 2019. Disponível em: $<$ http://www.revistatdh.org/index.php/Revista-TDH/article/view/53>. Acesso em: 16 fev. 2020.

SCHWAB, Klaus. The fourth industrial Revolution. World Economic Forum: Cologny/Geneva, Switzerland, 2016.

SILVA NETO, Manoel Jorge e. Direitos Fundamentais e o contrato de trabalho. São Paulo: LTr, 2005.

TECNOCRACIA. Os apps de transporte criaram uma dinâmica de trabalho de Robin Hood ao contrário. [S. 1.] Manual do usuário. 1 mai. 2019. Podcast. Disponível em: <https://open.spotify.com/episode/5koGIbrZjQ3GWhRN67gfyT>. Acesso em: 16 de fev. de 2020.

VILHENA, Paulo Emílio Ribeiro de. Valor: realidade, ficção ou projeção da realidade. Revista da Faculdade de Direito da Universidade Federal de Minas Gerais, Belo Horizonte, n 37, p. 235-259, 2000.

VILLELA, Fábio Goulart. A centralidade da Pessoa Humana na Ordem Jurídica e o Direito Social ao Trabalho Digno. In: MEDEIROS, Benizete Ramos de (Coord.). $O$ mundo do trabalho em movimento e as recentes altrações legismativas: um olhar luso-brasileiro. São Paulo: Ltr, 2018.

WESCHENFELDER, Germano Salvadori. Relações trabalhistas no modelo de negócios UBER. 2019. 60f. Trabalho de Conclusão de Curso (Graduação em Ciências Jurídicas e Sociais) - Universidade Federal do Rio Grande do Sul. Porto Alegre, 2019. 